\title{
DESAFIOS PARA UMA NOVA EDUCAÇÃO PATRIMONIAL
}

Simone Scifoni ${ }^{(*)}$

Ainda que as práticas educativas ligadas ao patrimônio estejam presentes no Brasil, desde o século XIX, junto à ação dos museus históricos, conforme lembra Chagas (2006), é forçoso reconhecer que, no país, a construção de uma fundamentação teórica para o que chamamos, hoje, de Educação Patrimonial é bastante incipiente. Particularmente no que diz respeito à reflexão sobre o trabalho educativo em museus avançou-se, entretanto, nem tudo que se contempla sob o rótulo de Educação Patrimonial acontece no espaço dos museus e nem sempre a reflexão que se faz neste campo pode servir ao trabalho que se organiza em outros tipos de instituições tais como escolas, órgãos de preservação, secretarias de educação e cultura, empresas de consultoria em arqueologia e, mais ainda, quando se trata de movimentos populares ou organizações da sociedade civil.

É justamente esta fragmentação da área, com os profissionais dispersos em diversas instituições de origem, bem como as dificuldades operacionais do cotidiano do trabalho, as quais tem impossibilitado o tempo necessário para a reflexão e formação teórica desses educadores, que têm criado obstáculos ao avanço e a consolidação desta base mais conceitual.

Neste sentido, o presente artigo pretende apresentar e debater algumas proposições teóricas essenciais para uma busca de renovação de um pensamento que elabora as práticas no campo da educação patrimonial. Parte-se da constatação de que é preciso superar as abordagens mais tradicionais e conservadoras nessa área, e que isso somente será possível com investimento em reflexão crítica e no campo conceitual.

Contudo, faz-se necessário, inicialmente, traçar uma breve problematização da trajetória mais recente do campo da Educação Patrimonial no Brasil para, então, iluminar as novas perspectivas abertas pela recente constituição de um marco legal neste campo, ou seja, das diretrizes elaboradas pelo Instituto do Patrimônio Histórico e Artístico Nacional (Iphan), constantes na portaria 137/2016. Partindo-se desta apresentação, o artigo procurará trazer ao debate algumas questões de natureza teórica que devem envolver a concepção das práticas. O que se pretende é,

\footnotetext{
${ }^{(*)}$ Doutora em Geografia pela Universidade de São Paulo. Professora do Departamento de Geografia da Faculdade de Filosofia, Letras e Ciências Humanas da Universidade de São Paulo. E-mail: simone.scifoni@gmail.com.
} 
acima de tudo, provocar uma reflexão sobre os limites e as possibilidades destas ações que têm sido produzidas no Brasil.

\section{OS PROBLEMAS DA EDUCAÇÃO PATRIMONIAL NO BRASIL}

Para não repetir uma abordagem já suficientemente aprofundada sobre a trajetória da educação patrimonial, com ênfase na experiência do Instituto do Patrimônio Histórico e Artístico Nacional (Iphan), elaborada por Oliveira (2011), Biondo (205) e Siviero (2015), a perspectiva que se adota aqui é a de apontar alguns obstáculos que, definitivamente, entravam a área.

O primeiro deles diz respeito às dificuldades atuais de constituição de um arcabouço conceitual fundamentador de um campo de reflexão. O impasse não se resume a existência de diferentes posições teóricas, mas a ausência de um único lugar de discussão no qual estas diferenças sejam contrastadas e debatidas. Este lugar de discussão não existe como unidade, mas está pulverizado em diversas nomenclaturas de campos, que atuam de forma pontual e isolada, muitas vezes autocentradas. Como avançar no pensamento se este se encontra fragmentado, sob várias denominações: educação patrimonial, ação educativa em museus, ação museal, educação para o patrimônio entre outras mais?

Esta dispersão surgiu a partir da recusa do uso do termo educação patrimonial, resultado da forma como ele foi publicizado, nos anos 1980. Ele apareceu como expressão, em 1983, durante um Seminário do Museu Imperial em Petrópolis $(\mathrm{RJ})$ e foi vinculado à determinada experiência em museus, trazida da Inglaterra. A expressão consagrou-se, nos anos 1990, com a publicação do Guia Básico de Educação Patrimonial do Iphan (HORTA; GRUNBERG; MONTEIRO, 1999), entretanto, contraditoriamente, também gerou forte recusa ao termo.

Isso porque, o Guia qualifica a expressão como uma determinada metodologia, aquela que é proposta na publicação, limitando, assim, as possibilidades de compreendê-la como aquilo que designa um campo de atuação e que pode, portanto, contemplar variadas e inúmeras metodologias. O Guia gerou uma série de críticas dos profissionais de museus, entre elas a de Chagas (2006) e Grinspun (2000), as quais se desdobraram na afirmação de outras denominações para esta mesma área. Embora com diferentes nomes, a perspectiva não deixou de ser comum, ou seja, de um trabalho educativo voltado à mobilização de saberes em torno do patrimônio, memória e da herança cultural, tanto em espaços da educação formal como informal. A constituição de um arcabouço conceitual passa, assim, por superar esta dispersão e fazer convergir esforços no sentido de criar uma perspectiva epistemológica para o campo da educação patrimonial. 
O segundo problema da educação patrimonial no Brasil é a permanência de "ideias fora do tempo", ou seja, formulações feitas no passado, que tinham sentido frente àquelas condições históricas pretéritas, mas que são repetidas à exaustão no presente, de forma acrítica e pouco reflexiva, como se fossem verdades universais e inquestionáveis.

“Conhecer para preservar" se encaixa neste jargão de ideias do passado utilizadas como verdades absolutas no presente, e que além de despolitizar o debate em educação patrimonial, impedem a realização de avanços na área. Concebida nos anos 1930, no momento de constituição oficial do Iphan, a afirmação de que a preservação do patrimônio passava, necessariamente, pelo seu conhecimento estava ligada, fundamentalmente, a novidade da legislação que estava sendo criada no país: a ideia de uma herança coletiva, objeto de tutela do Estado que não implicava em desapropriação e, para a qual, adotava-se um novo instrumento, o tombamento. Tal experiência, que já vinha acontecendo nos países da Europa, ou seja, a preservação do patrimônio, era inédita no Brasil e, neste sentido, era preciso esclarecer à população sobre a sua importância frente às condições daquele momento de franca expansão urbana-industrial, modernização e implantação de novas infraestruturas e, com isso, destruição do patrimônio. Acreditava-se, naquele momento, que era o desconhecimento deste ideal da preservação do patrimônio no Brasil e da existência de uma legislação protetora que levavam a demolições e desaparecimento de estruturas arquitetônicas como referenciais do passado.

Transposta para a realidade atual, tal noção apresenta-se como ingênua e despolitizadora do debate em educação patrimonial. Não somente porque cada vez mais o patrimônio está presente nos meios de comunicação e nos programas educativos, como é o caso dos Parâmetros Curriculares Nacionais, que desde os anos 1990, o adotaram como tema transversal, mas também porque ele tem se tornado, contemporaneamente, objeto de reinvindicação social. Ocupe Estelita, em Recife, ou o Movimento pelo Cine Belas Artes, em São Paulo, são exemplos recentes de um patrimônio que entrou na agenda política em função da organização e luta de grupos sociais nas grandes cidades.

Conhecer para preservar parte do pressuposto da ignorância da população a cerca de seu patrimônio e, mais ainda, credita a este sujeito indefinido - população - a fonte de todos os problemas do patrimônio. Despolitiza, assim, o debate, uma vez que culpabiliza um ser genérico, deixando de explicitar o que está por trás das dificuldades da preservação. Atitudes como a de proprietários privados, que abandonam seus imóveis nos centros históricos, sem qualquer medida de conservação e que o fazem intencionalmente, para causar a deterioração física, são realmente fruto do desconhecimento do valor dessas edificações, muitas delas herança de família, ou são resultado do interesse pelo lucro com a demolição e venda do terreno? 
“Conhecer para preservar” é uma campanha que deve ser levada, principalmente, à esfera do poder público, junto aos vereadores de câmaras municipais, prefeitos, governadores, deputados do legislativo, que, não raramente, pressionam os órgãos públicos para aprovações de empreendimentos que causam a perda física ou de significados dos bens culturais.

Deve ser enfatizada, também, junto aos empreendedores imobiliários que têm destruído sistematicamente os suportes materiais de memória coletiva nas cidades brasileiras, produzindo aquilo que Carlos (2001) chamou de espaço amnésico. Nas palavras da autora, se a cidade só existe pela acumulação de tempos do passado, a perda dos referenciais urbanos, que se dá pela rápida transformação do ambiente construído, nos faz mergulhar na vertigem do vácuo, em um sentido de estranhamento em relação aos lugares da vida, que se manifesta como sentimento do desconhecido e da perda de identidade com o lugar.

Conhecer para preservar é, igualmente, uma lição que deve ser difundida entre os próprios gestores públicos do patrimônio que, muitas vezes, têm dado exemplos de aprovações de intervenções e licenciamento de obras que, contraditoriamente, causam destruição ou descaracterização do próprio objeto de sua tutela. O processo de flexibilização, ajuste e desregulamentação do patrimônio cultural, discutido em Scifoni (2015), que se realiza a partir de alterações ou revogação de normativas de tombamento com a finalidade precípua de liberar empreendimentos, tem resultado no desaparecimento de bens culturais ou na perda de seus sentidos e significados.

Aos educadores cabe superar esta discussão do passado, situando o patrimônio no século XXI, dentro da realidade complexa de interesses e ações público-privadas. Reproduzir acriticamente frases de efeito da década de 1930, de forma descontextualizada, tem levado a educação patrimonial a práticas equivocadas, que deixam claro as fragilidades conceituais a que está submetida.

Outro conjunto de problemas neste campo tem relação com a lógica que as instituições de cultura e de patrimônio estão atualmente submetidas: a da cultura como mercado e como negócio, na qual a meta fundamental se expressa em valores quantitativos, ou seja, público. Mais do que a qualidade do trabalho educativo ou da problematização da memória/produção do esquecimento, as instituições voltadas a este mercado da cultura, preocupadas com formação de público em volume necessário para justificar os gastos (que deveriam ser compreendidos como investimento social), tem transformado os educativos em linha de produção de conteúdos repetitivos, pouco dialogados ou criativos. A constituição destes serviços educativos, muitas vezes delegadas a instituições 
privadas como as organizações sociais (OS), tem subtraído dos educadores o seu papel de sujeito ativo, criativo e reflexivo, transformando-os em meros estagiários mal remunerados e reprodutores de conteúdos, desmotivando seu próprio trabalho.

A cultura na lógica do privado, como negócio lucrativo, não é compatível com reflexão crítica, com problematização e nem com compreensão do significado do passado. Como diz Harvey (1992), o tratamento dado ao passado vira espetáculo, encenação, re-presentação de costumes, que ao invés de conduzir a uma compreensão profunda da história, leva a superficialidade, à semelhança de uma tela oca, esvaziada de conteúdo.

Por fim, na lista dos problemas que entravam, hoje, a educação patrimonial, é importante lembrar das dificuldades geradas pela criação de um segmento de mercado em torno dos licenciamentos ambientais e da arqueologia de contrato. Desde que a antiga Portaria 230/2002 do Iphan, instituiu a necessidade de Programa de Educação Patrimonial, no âmbito da aprovação de projetos que interferissem em sítios arqueológicos, multiplicaram-se ações educativas como forma de cumprir a exigência.

O que poderia ser, em si, um fator positivo no sentido de ampliar as práticas de educação patrimonial, ao contrário, acabou se traduzindo em uma enorme produção de folhetos e cartilhas sobre arqueologia, direcionados às escolas públicas, mas sem qualquer relação com os conteúdos de sala de aula e com linguagem excessivamente técnica, autocentrada e desvinculada de uma relação maior com o patrimônio cultural. Além de gerar uma grande quantidade de material estéril, pouco sensibilizador das questões de proteção da memória e do patrimônio, investe-se, mais recentemente, na produção de material lúdico como cruzadinhas, jogo dos sete erros, ligue os pontos e atividades afins. O que pode parecer uma inovação, na verdade, mostra-se mais uma vez estéril do ponto de vista da problematização do patrimônio. Investe-se mais em fixar imagens, no caráter informativo, em atividades mecânicas ou para favorecer habilidades manuais, à semelhança das revistas de palavras-cruzadas compradas em uma banca de jornal. Questiona-se se tais atividades lúdicas realmente sensibilizam as novas gerações para a preocupação com a memória coletiva ou o patrimônio ou se trata de uma simples distração ou passatempo, independente de seu conteúdo.

Com a recente publicação da Instrução Normativa 01 de 2015, que substitui a Portaria 230, espera-se mudanças no tratamento dado às ações educativas, uma vez que se instituiu a exigência de um Plano Integrado de Educação Patrimonial, que deve explicitar a sua concepção, metodologia e forma de implementação, conforme discriminam os artigos 43 a 45. Estabelece-se, também, que as palestras e publicação de material promocional dos empreendimentos ou empresas, tão 
frequentemente usadas como artifícios para compor as exigências da educação patrimonial, não mais serão consideradas como tal. Vislumbra-se, assim, que haja mudança na esfera do licenciamento ambiental e da arqueologia de contrato, no sentido de maiores investimentos em projetos voltados e articulados às realidades nos quais as intervenções se situam.

Além das novidades colocadas pela Instrução Normativa para a educação patrimonial, a recente instituição de um marco legal para o campo, ou seja, a Portaria 137/2016, deve estimular, também, uma reorientação de práticas, uma vez que, doravante, devem seguir princípios como: favorecer a participação social nas ações educativas; integrá-las no cotidiano e na vida das pessoas; compreender o território onde se atua como espaço educativo; fomentar a relação de afetividade em relação aos bens culturais; e, principalmente, reconhecer que as práticas educativas se inserem em um campo de negociação e conflito entre diferentes grupos sociais.

Essa portaria, acompanhada, na sequência, da publicação da metodologia dos inventários participativos (IPHAN, 2016), representam, assim, um deslocamento da matriz em educação patrimonial, no mesmo sentido que Meneses (2009) atribuiu ao papel da Constituição Federal de 1988, em relação ao Decreto-Lei 25 de 1937. Segundo o autor, a Constituição Federal deslocou a matriz de valoração, anteriormente centrada no Estado, agora para a sociedade, uma vez que reconheceu que os valores culturais não são criados pelo poder público, mas têm como ventre gerador a própria sociedade, esclarecendo, portanto, que o papel do Estado é declaratório e protetor e não instituinte.

No caso da educação patrimonial, os novos instrumentos institucionais criados pelo Iphan, da mesma forma, deslocam a matriz das ações educativas daquilo que era legalmente protegido pelo tombamento ou registro, para as referências culturais, portanto, para aquilo que, mesmo não sendo institucionalizado, tem sentido e significado para os diferentes grupos sociais.

Assim sendo, espera-se que a criação do marco legal, acompanhado de nova inspiração metodológica, possa estimular não somente o segmento da arqueologia de contrato e das consultorias ambientais, mas, também, outras instituições, a trilhar novos caminhos mais desafiadores e problematizadores da construção da memória oficial.

Frente ao conjunto de problemas brevemente tratados aqui, os quais têm limitado não só as práticas, mas também a reflexão teórica sobre este campo em construção, pergunta-se: quais estratégias teórico-conceituais podem ser pensadas em busca de sua superação? 


\section{ALGUMAS PROPOSIÇÕES PARA UMA NOVA PEDAGOGIA DO PATRIMÔNIO}

O que é patrimônio cultural, cultura, identidade e memória: muitas das atividades voltadas à formação em educação patrimonial principiam introduzindo esses conceitos, e o próprio Guia Básico do Iphan não foge ao mesmo tipo de abordagem. No entanto, quando se pensa que a finalidade do trabalho é sensibilizar as novas gerações a pensar sobre a necessidade da preservação, pergunta-se: não seria um equívoco partir de conceitos abstratos, principalmente em se tratando de um público escolar, formado por crianças, mas, mesmo também, em relação aos jovens?

Para Vygotsky (1987), o processo de formação de conceitos é complexo e não se dá meramente como ato mecânico, de transmissão do professor ao aluno, já que se trata de apreendê-lo por meio de intensa atividade mental. Sendo assim, não teria sentido promover o ensino direto de conceitos, o que para o autor é infrutífero.

Um professor que tenta fazer isso geralmente não obtém qualquer resultado, exceto o verbalismo vazio, uma repetição de palavras pela criança, semelhante a de um papagaio que simula um conhecimento de conceitos correspondentes, mas que na realidade oculta um vazio. (VYGOSTKY, 1987, p. 72).

Mesmo considerando que, entre os jovens ou um público adulto leigo, a base psicológica para a formação de conceitos já está amadurecida e desenvolvida, este, ainda, seria um ponto de partida estéril quando se pensa na sensibilização e problematização das questões do patrimônio. Investir em assimilação de conceitos ofertados, prontos e acabados, é considerar nossos interlocutores como receptáculos vazios, como objetos a intervir e não como sujeitos do processo. Apresentar conceitos, antes de construir uma possibilidade de entendimento a partir da realidade vivida, é negar a possibilidade de nossos interlocutores se perceberem como sujeitos de sua cultura, da história e do mundo. Trata-se, enfim, da apreensão do conceito de patrimônio cultural e não de sua transmissão mecânica.

Conceitos são construídos no desafio e por meio do estímulo com o contexto no qual os sujeitos estão emersos e, neste sentido, o início é sempre a realidade e a experiência prática, a partir da qual se chega ao que pode ser definido como cultura, memória, identidade e patrimônio. Neste sentido, o movimento vai da realidade em direção à construção de conceitos, esse desempenhando a etapa final do processo. Inverte-se, assim, a forma como, tradicionalmente, a educação patrimonial tem atuado.

Para iniciar a abordagem pela realidade dos grupos com os quais se atua, sem antes apresentar os conceitos pontos, significa mobilizar aquilo que se encontra na essência do patrimônio 
cultural: os sentidos ligados à permanência e a guarda de objetos, como parte de um conjunto de necessidades humanas, como algo existencial.

Fotos antigas, roupas de infância, álbuns de figurinhas, brinquedos antigos, toda pessoa guarda algum tipo de objeto que remete a experiência vivida em seu passado, ainda que ele seja muito recente. A guarda destes objetos pessoais se dá na medida em que cada um deles é capaz de mobilizar lembranças, necessárias a compreensão do que somos como indivíduo humano, ou seja, da formação de uma identidade. São exemplos do que Bosi (2010) chamou de objetos biográficos, expressão que a autora tomou emprestado, originariamente, de Violette Morin.

Se a mobilidade e a contingência acompanham nosso viver e nossas interações, há algo que desejamos que permaneça imóvel, ao menos na velhice: o conjunto dos objetos que nos rodeiam. Nesse conjunto amamos a quietude, a disposição tácita mas expressiva. Mais que um sentimento estético ou de utilidade, os objetos nos dão um assentimento à nossa posição no mundo, à nossa identidade. Mais do que ordem e beleza falam à nossa alma em sua doce língua natal. (BOSI, 2010, p. 441).

Quando objetos biográficos são trazidos à discussão nos grupos em que se atua, e estes são instigados a falar sobre o que eles indicam a respeito da própria existência, mobilizam-se os conceitos de identidade e memória, a partir da prática. Provocar o grupo a pensar sobre a possibilidade da perda destes objetos, por outro lado, ajuda a compreender que a permanência destes tem um papel existencial, na composição dos indivíduos.

Abordados, assim, a partir de uma perspectiva inicial que é individual e pessoal, os objetos biográficos revelam, entretanto, a possibilidade de ampliar e transpor a discussão e os conceitos mobilizados, na prática, para outra escala: a da cidade. Uma esquina, um muro, uma praça, um edifício, também, fazem parte da memória daqueles que vivem a cidade, são objetos biográficos para determinados grupos sociais, pois, a partir deles, é possível mobilizar lembranças da infância, da escola, do trabalho, em uma cidade que se transforma de maneira rápida. O sentido social atribuído a estes objetos ultrapassa a sua finalidade prática, seu papel na cidade é de ordem simbólica, conforme explicita Baudrilhard (2009). Para o autor, estes desempenham um papel testemunhal, de lembrança, um signo de sistemas culturais anteriores, cujo valor é de historicidade, trazendo o significado do tempo. O tempo-espaço do vivido.

Mais uma vez, provocar o grupo a pensar nas perdas reais destes suportes de memória coletiva da cidade, pela transformação imposta ao espaço urbano, ajuda a compreender a necessidade e as razões da preservação, uma vez que não se trata apenas de transformação, mas de destruição do espaço vivido, no qual os sujeitos podiam reconhecer sua própria existência. 
Em que pese as argumentações da bibliografia estrangeira sobre uma tendência contemporânea de patrimonialização excessiva e dever de memória, conforme Jeudy (2005), ou de uma inflação patrimonial, como explicita Choay (2001), em relação a realidades de países como o Brasil, este excesso de conservação não se efetivou e a realidade tem mostrado que as ameaças aos suportes materiais de memórias coletivas nas cidades ainda é muito presente. Ao contrário de um boom de memória e patrimônio, como sinalizam Santos e Marques (2014), vive-se, em países latino-americanos, como o Brasil, uma dinâmica urbana tensionada pelas forças do mercado imobiliário que impõem a lógica da cidade como negócio e tem eliminado traços fundamentais da história cotidiana, tais como antigos cinemas ou teatros, ou exemplares do morar das classes populares e uma grande parte da herança industrial, fenômeno que vem acompanhado por graves problemas sociais, tais como a expulsão dos grupos mais pobres dos centros.

Deterioração física de bens culturais pelo abandono e ausência de medidas de conservação, o famoso deixar cair; demolições de edificações antigas, legalmente não protegidas, e sua substituição por novas estruturas como condomínios residenciais ou shoppings, como espaços homogêneos e normatizados; projetos estatais de intervenção e criação de infraestrutura que dilapidam e fragmentam conjuntos tombados; são alguns dos exemplos de perda do patrimônio que as cidades brasileiras acompanham cotidianamente. Este processo, chamado de urbicício, segundo Mena (2014), está muito mais presente nas cidades latino-americanas do que um pretenso boom de memória e de patrimônio.

Este é, portanto, o motor que deve alimentar a reflexão da educação patrimonial, porque envolve pensar, não no patrimônio como objeto reificado, mas no que se deseja para a cidade e o lugar em que se habita e vive. É preciso pensar, conforme os termos propostos por Bensaid (2008, p.9), que [...] "a herança não é uma coisa inerte ou um capital que se põe no banco, mas que ela existe e é apenas o que dela fazem (e farão) os herdeiros [...]”.

Neste sentido, o compromisso da educação patrimonial deve superar a ideia da transmissão da cultura e da informação, para entendê-lo como processo de formação da consciência crítica sobre a realidade que pode possibilitar o reconhecimento das pessoas como sujeitos de sua própria história e cultura, capazes de agir em busca das transformações necessárias.

Finalizando, a educação patrimonial que se proponha a ser renovadora, deve partir, necessariamente, desta problematização da realidade e das políticas de patrimônio no país, desmistificando ideias conservadoras do passado, superando os limites de uma ação tradicionalista fundada na transmissão de informações e conteúdos. Mudar as práticas é, assim, essencial. 
Mas a renovação, também, deve vir da necessidade de construir, de forma coletiva, um arcabouço teórico-conceitual capaz de fundamentar essas novas práticas e um novo pensamento. E o que se buscou aqui foi trazer para a discussão alguns destes aportes teóricos, de autores que compõe uma bibliografia sobre patrimônio e memória, mas que nem sempre são incorporados à discussão da educação patrimonial. 


\section{REFERÊNCIAS}

BAUDRILLARD, J. O sistema dos objetos. 5. ed. Trad.: Zulmira R. Tavares. São Paulo: Perspectiva, 2009.

BENSAID, D. Os irredutíveis. Teoremas da resistência para o tempo presente. Trad.: Wanda C. Brant. São Paulo: Boitempo, 2008.

BIONDO, F. Desafios da Educação no Campo do Patrimônio Cultural: Casas do Patrimônio e Redes de Ações Educativas. Dissertação (Mestrado em Preservação do Patrimônio Cultural) - Iphan, Rio de Janeiro, 2015.

BOSI, E. Memória e sociedade. Lembrança de velhos. São Paulo: Companhia das Letras, 2010.

CARLOS, A.F.A. Espaço-tempo na metrópole. A fragmentação da vida cotidiana. São Paulo: Contexto, 2001.

CHAGAS, M. Educação, museu e patrimônio: tensão, devoração e adjetivação. Dossiê Educação Patrimonial, n. 3, Iphan, jan./fev. 2006.

CHOAY, F. A alegoria do patrimônio. São Paulo: Unesp, 2001.

GRINSPUM, D. Educação para o patrimônio. Museu de Arte e escola. Responsabilidade compartilhada na formação de públicos. Doutorado (Tese em Educaç) - Faculdade de Educação, Universidade de São Paulo. 2000.

HARVEY, D. A condição pós-moderna. 5. ed. Trad.: Adail U. Sobral e Maria Stela Gonçalves. São Paulo: Loyola, 1992.

HORTA, M.L.P.; GRUMBERG, E.; MONTEIRO, A.Q. Guia Básico de Educação Patrimonial. Brasília: Instituto do Patrimônio Histórico e Artístico Nacional, Museu Imperial, 1999.

JEUDY, H. Espelho das cidades. Trad.: Rejane Janowitzer. Rio de Janeiro: Casa da Palavra, 2005.

IPHAN. INSTITUTO DO PATRIMÔNIO HISTÓRICO E ARTÍSTICO NACIONAL. Portaria 230, de 17 de dezembro de 2002. Rio de Janeiro, Departamento do Patrimônio Material, Diário Oficial da União, Poder Executivo, Brasília, 18 Dez. 2002, sec. 1, n. 244.

. Instrução Normativa n. 01, de 25 de março de 2015. Estabelece procedimentos administrativos a serem observados pelo Instituto do Patrimônio Histórico e Artístico Nacional nos processos de licenciamento ambiental dos quais participe. Diário Oficial da União, Poder Executivo, Brasília, 26 mar. 2015, sec. 1, n. 58, p. 11.

. Portaria 137, de 28 de abril de 2016. Estabelece diretrizes de Educação Patrimonial no âmbito do Iphan e das .Casas do Patrimônio. Diário Oficial da União, Poder Executivo, Brasília, 29 abr. 2016, sec. 1, n. 81, p. 06.

. Educação Patrimonial: Inventários Participativos. Manual de Aplicação. Brasília: Coordenação de Educação Patrimonial/Iphan, 2016.

OLIVEIRA, C.A.P. Educação Patrimonial no Iphan. Monografia (Especialização) - Escola Nacional de Administração Pública (ENAP), Brasília, 2011.

MENA, F. C. Urbicidio o la noción del olvido. XV Seminario sobre Patrimonio Cultural, 2014, Chile.

MENESES, U. T. B. O campo do patrimônio cultural: uma revisão de premissas. In: I Fórum Nacional de Patrimônio Cultural. Brasília: Iphan, 2012. vol.1.

SANTOS, C.R.; MARQUES, S. Maldita memória. Sobre a tirania da memorização e os anacronismos de um patrimônio refém. Arquitextos, São Paulo, ano 15, n. 175, dez. 2014. Disp.: <http://www.vitruvius.com.br/revistas/ read/arquitextos/15.175/5373>. Acesso: 02 mar. 2016.

SCIFONI, S. Patrimônio como negócio. In: CARLOS, A.F.A. et al. (Org.). A cidade como negócio. São Paulo: Contexto, 2015. p. 209-225.

SIVIERO, F. Educação e patrimônio cultural: uma encruzilhada nas políticas públicas de preservação. Revista CPC, n. 19, p. 80-108, jun. 2015.

VYGOSKY, L.S. Pensamento e linguagem. São Paulo: Martins Fontes, 1987. 


\section{RESUMO}

Este artigo pretende debater algumas proposições teóricas fundamentais para a renovação de um pensamento sobre as práticas no campo da educação patrimonial, partindo-se da constatação da inexistência, no Brasil, de uma base teórica consistente que permita superar as abordagens mais tradicionais e conservadoras. Inicia-se com uma problematização da trajetória deste campo, no Brasil, para em seguida colocar em debate algumas questões de natureza teórica que envolvem a concepção das práticas. $\mathrm{O}$ que se pretende é, sobretudo, provocar uma reflexão sobre os limites e as possibilidades destas ações que têm sido produzidas no Brasil.

Palavras-chave: Educação patrimonial. Pedagogia do patrimônio. Práticas educativas.

\section{RETOS PARA UNA NUEVA EDUCACIÓN PATRIMONIAL}

\section{RESUMEN}

Este artículo pretende debatir algunas propuestas teóricas fundamentales para la renovación de un pensamiento sobre las prácticas en el campo de la educación patrimonial, a partir de la constatación de la inexistencia, en Brasil, de una base teórica consistente que permita superar los enfoques más tradicionales y conservadores. Se inicia con una problematización de la trayectoria de este campo, en Brasil, para poner en debate algunas cuestiones de naturaleza teórica que implican la concepción de las prácticas. Lo que se pretende, es, sobre todo, provocar una reflexión sobre los límites y las posibilidades de estas acciones que han sido producidas en Brasil.

Palabras-clave: Educación patrimonial. Pedagogía del patrimônio. Prácticas educativas.

\section{CHALLENGES FOR A NEW HERITAGE EDUCATION}

\section{ABSTRACT}

This article aims to discuss some fundamental theoretical propositions for a renewed vision for heritage education practices, based on the observation that, in Brazil, this field lacks a consistent theoretical basis that allows it overcome the most traditional and conservative approaches. The article begins by problematizing the history of heritage education in Brazil, and moves on to discuss theoretical issues concerning the concept of its practices. The aim, above all, is to stimulate a reflection on the limits and possibilities of the actions that have been undertaken in Brazil.

Keywords: Heritage education. Heritage pedagogy. Educational practices.

Submetido em: Ago. 2016

Aprovado em: Dez. 2016 